\title{
Polymeric Composites Based on Polyurea Matrix Reinforced with Carbon Nanotubes
}

\author{
MARIA ADINA VULCAN ${ }^{1}$, CELINA DAMIAN ${ }^{1}$, PAUL OCTAVIAN STANESCUㄴ, EUGENIU VASILE², RAZVAN PETRE³, \\ GHEORGHE HUBCA ${ }^{1 *}$ \\ ${ }^{1}$ University Politehnica of Bucharest, Department of Bioresources and Polymer Science,1-7 Gh.Polizu Str., Bucharest, Romania \\ 2 University Politehnica of Bucharest, 1-7 Gh.Polizu Str., 011061, Bucharest Romania \\ ${ }^{3}$ Scientific Research Center for CBRN Defense and Ecology, 225 Oltenitei Av., 041309, Bucharest, Romania
}

\begin{abstract}
This paper deals with the synthesis of polyurea and its use as polymer matrix for nanocomposites reinforced with multi-walled carbon nanotubes (MWCNT). Two types of materials were obtained during this research, the first cathegory uses the polyurea as matrix and the second one uses a mixture between epoxy resin and polyurea. The nanocomposites were characterized by Thermogravimetric Analysis (TGA), Dynamic Mechanical Analysis (DMA), Scanning Electron Microscopy(SEM) and Tensile Tests. The elastomeric features of nanocomposites were highlighted by the results which showed low value of Tg. Also higher thermal stability with $\sim 40^{\circ} \mathrm{C}$ compared with commercial products (M20) were observed, but lower mechanical properties compared to neat polyurea.
\end{abstract}

Keywords: polyurea, epoxy resins, MWCNT, nanocomposites

Polyurea is a heterochain macromolecular compound which contains urea groups in the backbone structure. The synthesis of this type of polymer consist in the polyaddition of an amine to a diisocyanate. Depending on the nature of the components which are implied in the process, polyurea may have aliphatic or aromatic structure. Aliphatic linear polymers are thermoplastic products whose difference between melting temperature and decomposition temperature is between $50-100^{\circ} \mathrm{C}$ [1]. Polyureas which contains aromatic structures have the melting temperature close to the decomposition temperature.

Polyurea is currently the most successful material used in industrial coatings. This is determined by many factors as: progress in the polyurea synthesis and application technology, high rate of curing at relatively low temperatures [2], high chemical resistance, moisture impermeability, excellent mechanical properties (high flexibility, tear, abrasion and tensile strength), low flammability and excellent durability[3]. Due to this properties, polyurea is superior to the polyurethanes. Due to these properties, polyurea materials are superior to polyurethanes. The advantage of the polyurea use in the coating domain consist in the absence of any solvent or any volatile organic compound which allows the use of a suitable processing equipment by spraying the two components (the diisocyanate and the diamine). The spray process was developed in the 90s and nowadays constitutes the main technology for polyurea coatings [35].

A special interest was gained by the coatings used for structures and components exposed to severe dynamic and impulsive tests caused by explosions, where the energy dissipation capacity considerably limits the destruction of the structures. By applying polyurea on the inside surfaces of buildings could prevent the breakage, the collapse or fragmentation of structures in case of explosion [6-8]. High resistance to impact determined the successful use of polyurea in the ballistic field. Dynamic response of metal / polyurea composites was studied by numerical methods as well as experimental methods.
Several studies deal with the test of steel plate composites coated with a thin coating of polyurea [3,9-12], as well as aluminum plates coated with polyurea [13-15]. To improve the polyurea properties, nanocomposites were obtained using MWCNT, nanoclays or POSS as nanofiller [16-23].

This paper aims the study of the properties of nanocomposites reinforced with MWCNT, using polyurea and epoxy/polyurea as polymer matrices.

\section{Experimental part}

For the experimental determinations the following materials were obtained: nanocomposites reinforced with MWCNT based on polyurea synthesized in the laboratory

Raw materials:

-The polyether amine with molecular weight 2000 (J effamine D2000) acquired from Huntsman was used as received.

$-4,4^{\prime}$-diphenylmethane diisocyanate (Desmodur $44 \mathrm{~V} 20 \mathrm{~L}$ ) with $30.5-32.5 \%$ NCO groups, purchased from Bayer, was used as received .

-diglycidyl ether of bisphenol A type epoxy resin (A506), with epoxy equivalent 172-185 g/eq was supplied by SigmaAldrich and used as received.

-As nanofiller multi-walled carbon nanotubes (MWCNT) functionalized with hydroxyl groups acquired from Cheap Tubes were used.

Hereinafter is presented the procedure for the synthesis of polymeric matrices and their nanocomposites:

a)The synthesis of polyurea was done using acetone as solvent for a molar ratio of diisocyanate:amine $=1: 1$, at room temperature. After synthesis the mixture was poured in the mould left for $24 \mathrm{~h}$ at room temperature for acetone evaporation, then the polyurea samples were put in an oven at $50^{\circ} \mathrm{C}$ for $12 \mathrm{~h}$.

b) The combined polyurea-DGEBA matrices were obtained by adding the epoxy resin simultaneously with polyurea synthesis. The resulting material followed the same procedure as in the method a).

c) Polyurea/MW CNT nanocomposites were obtained by dispersing $1 \%$ wt. nanofiller in the diamine solution using tip ultrasonicator for $1 \mathrm{~h}$. After that, the resulting dispersion

\footnotetext{
*email: gheorghe_hubca@yahoo.com
} 


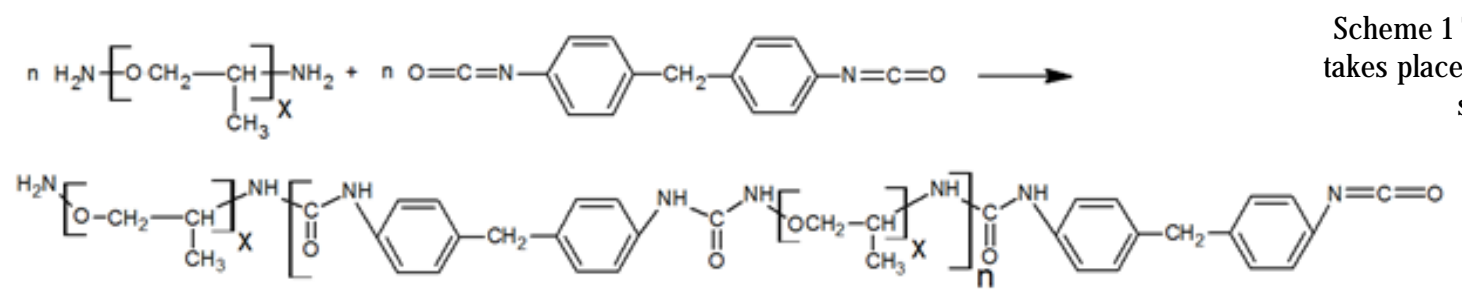

Scheme 1 The reaction which takes place in case of polyurea synthesis

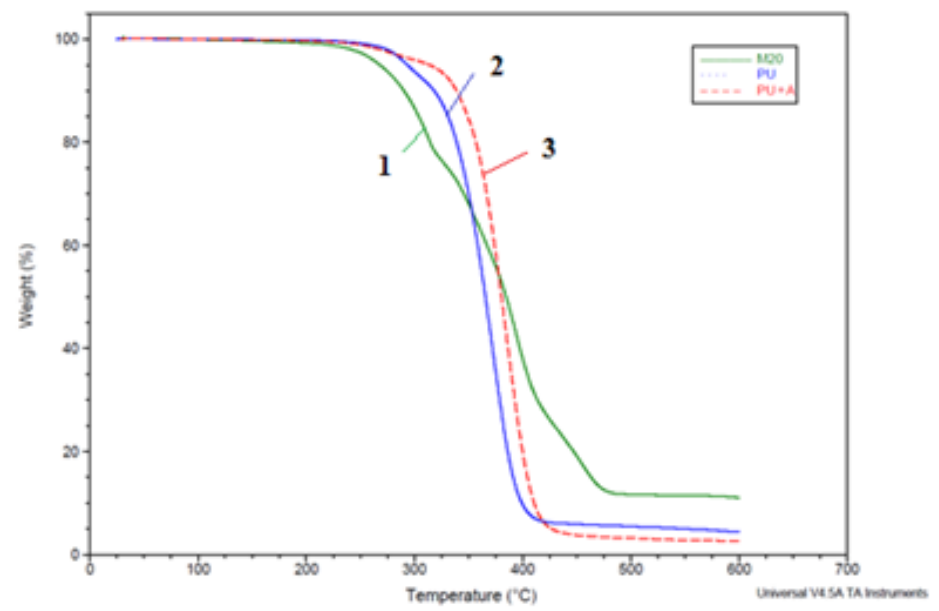

Fig.1. TGA curves recorded for polymeric matrices 1-Polyurea from spray gun (M20); 2-Polyurea obtained in laboratory (PU); 3-Epoxy-polyurea matrix (PU+A)
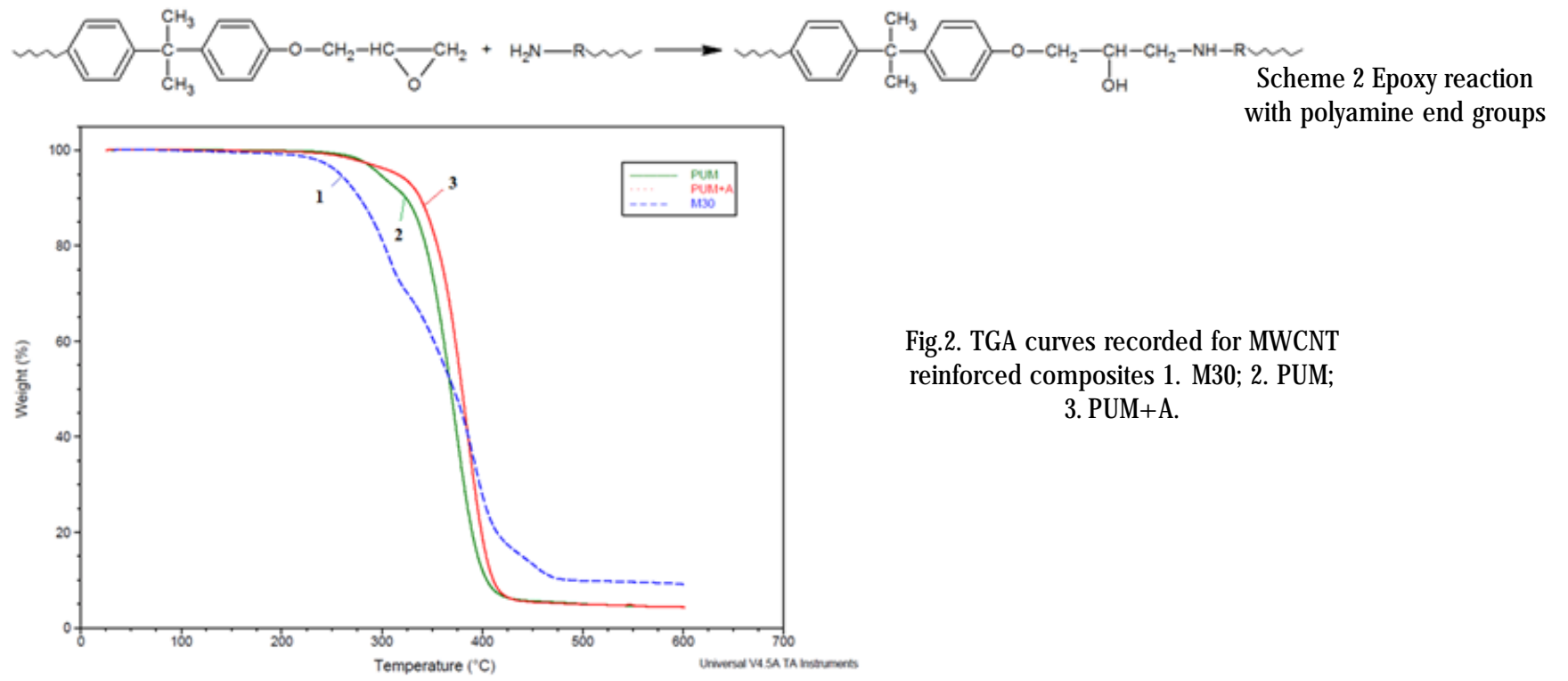

Fig.2. TGA curves recorded for MWCNT reinforced composites 1. M30; 2. PUM; 3. $P U M+A$.

was mixed with the diisocyanate in acetone solution. Further, the sample was processed as described in the method a).

d) The nanocomposites having combined polyurea/ DGEBA matrices were obtained in the following way: the carbon nanotubes were dispersed by ultrasonication for 2 $h$ in $A 506$ resin, then the mixture was introduced in diisocyanate/ diamine solution in the same way as described in the method a).

Based on the synthesized polyurea (PU) the following composite materials were obtained: reinforced polyurea with 1\% MWCNT (PUM), polyurea in mixture with A506 epoxy resin (PU+A) and a composite with epoxy-polymer matrix reinforced with $1 \% M W C N T(P U M+A)$.

\section{Results and discussions}

The two types of polymeric matrices (PU and PU+A) as well as its 1\% MWCNT reinforced composites was characterized by thermogravimetric analysis (TGA) on a Q500 TA Instruments equipment, under nitrogen atmosphere, using a heating rate of $10^{\circ} \mathrm{C} / \mathrm{min}$ from room temperature to $600^{\circ} \mathrm{C}$.
The TGA curves for polymeric matrices without reinforcing material (fig.2) show a synergistic effect probably due to the addition of epoxy resin in the combined matrix, leading to a higher thermal stability. Compared with the neatpolyurea, the value of thermal stability (considered the temperature at which $3 \%$ of the sample is lost $\mathrm{T}_{\mathrm{d} 3 \%}$ ) for the nanocomposites was higher with almost $40^{\circ} \mathrm{C}$.

A synergistic effect on the thermal stability is also recorded for the MWCNT reinforced composites (fig.3). Epoxy resin addition synergistic effect is due the epoxy groups reactivity which interact with the amine end groups from polyurea.

The synergistic effect of epoxy resin addition on the polyurea and 1\% MWCNT reinforced composites concerning the thermal stability is presented in table 1.

Dynamic mechanical analysis recorded on a TRITEC $2000 \mathrm{~B}$ instrument at $1 \mathrm{~Hz}$ frequency for unreinforced matrices as well as for the composites showed a synergistic effect shown in figure 4, regarding the glassy state of used components. The DMA data were collected from -5 to $180^{\circ} \mathrm{C}$. Data analysis recorded by DMA highlighted the rubber character of neat polyurea as well as MWCNT 
Table 1

THE THERMAL STABILITY DATA OF POLYUREA AND NANOCOMPOSITESSAMPLES

\begin{tabular}{|ccccccc|c|}
\hline Sample & PU & PUM & PUA & PUM+A & M20 & M30 \\
\hline Td3\%(^C) & 282.8 & 286.2 & 283.5 & 289.4 & 254 & 245.72 & a) \\
\hline $\begin{array}{c}\text { Mass } \\
\text { loss }(\%)\end{array}$ & 97.7 & 96.1 & 97.4 & 95.7 & 90.2 & 92.7 \\
\hline
\end{tabular}

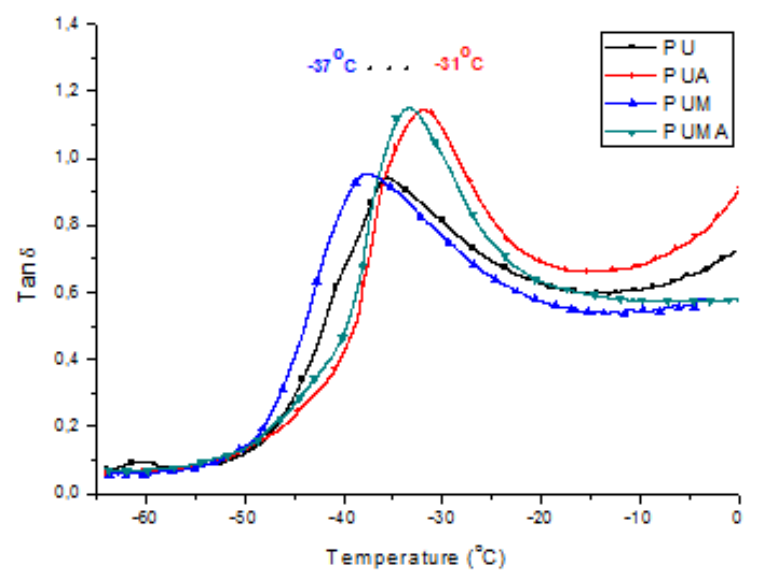

Fig.3. Tg values determined by DMA for PU matrices and MWCNT reinforced composites

reinforced composites, $\mathrm{Tg}$ values being situated much below $0^{\circ} \mathrm{C}$. How ever the introduction of epoxy increases the Tg values of the samples beside the reinforcing ability of MWCNT. This is in accordance with the literature data which shows that in case of polyurea occurs also an intrinsic auto-reinforcing process by its morphology [23].

The hydroxyl groups anchored on MWCNTs have the ability to react with reactive isocyanate groups from the end of the PU chain (scheme 3), but in the same time the reaction of hydroxyl groups could take place with the epoxy groups from DGEBA. In these conditions, the properties of nanocomposites will largely depend upon filler dispersion grade in the polymer matrix.

SEM micrographs were recorded using a Quanta Inspect $F(F E I)$ instrument with field emission electron gun, 1.2 $\mathrm{nm}$ resolution and $X$-ray energy dispersive spectrometer having an accelerating voltage of $30 \mathrm{kV}$. For better contrast, the samples were first fractured in liquid nitrogen and covered with a thin gold layer. The images of the fracture surface are showing a fairly uniform distribution of carbon nanotubes in polymer matrix (fig.4) considered to the white points arises from the dark matrix.

Polyurea self assembling in a continuous elastomeric matrix with self interconnected and nanometric rigid domains dispersed into polyurea structure represents an ideal filler/polymer composite.

However, carbon nanotubes presence in polyurea could determine the improvement of thermostability, stiffness, modulus increase, and the improvement of tribological properties of nanocomposites [25].

\section{Conclusions}

The process for the synthesis of nanocomposites based on polyurea was studied and the following conclusions could be pointed out:

-MWCNT and DGEBA resin addition has a synergistic effect causing the improving of thermal stability and the glass transition temperature $(\mathrm{Tg})$ value.
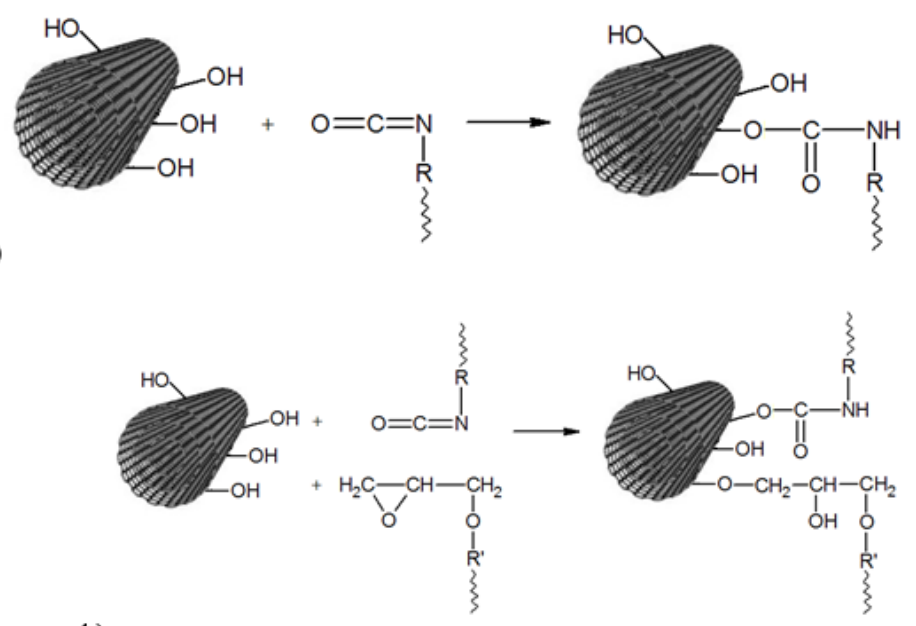

b) Scheme 3. Possible interactions of MWCNT with PU (a) and with $P U+A(b)$

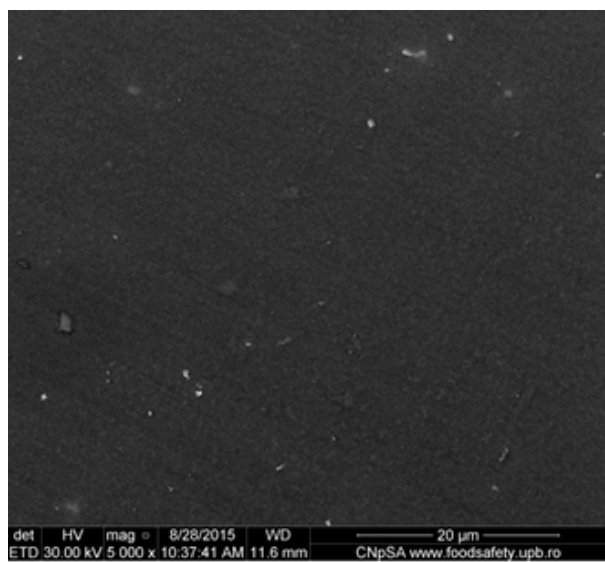

Fig.4. SEM micrograph of PU+1\%MWCNT composites

-SEM analysis show ed a uniform distribution of carbon nanotubes in polymer matrix

-DMA analysis of nanocomposites with MWCNT reinforced PU matrices have highlighted its elastomeric character.

-Composites tensile strength is inferior to neat polyurea fact which is due to a self reinforcing effect by dispersion of rigid domains in continuous elastomeric matrix. Because of this, polyurea isn't a great candidate for nanofillers, which is in agreement with published data in specialty literature[24].

Acknowledgement: Authors aknowledge Ministry of National Education for fundind through projet PN-II-PT-PCCA-2013-4-0707 no. 285/2014. The SEM analyses on samples were possible due to EUfunding grant POSCCE-A2-02.2.1-2013-1/Axa prioritara 2, Project No. 638/12.03.2014, cod SMIS-CSNR 48652

\section{References}

1.J OSHI, M.; J AUHARI, S.; J ournal of Materials Engineering and Performance, 21, no.7, 2012, p.1346.

2.DAVIS, T.; EBERSOLE, F.; J. Am. Chem. Soc., 56, 1934, p 885.

3.GHEZZO, F.; MIAO, X.; IMSE, 1, no. 2, 2014, p.66.

4.CHOI, H.; TOUTANJ I, H.A.; GILBERT, J .A.; ALIDREDGE, D.J., J . Mater. Civ. Eng., 25, no. 12, 2013, 1984.

5.PRIMEAUX DUDLEY, J.; u.s. Patent 5118728, J un. 2, 1992.

6.GHEZZO, F.; MIAO, X.; $11^{\text {th }}$ International Conference on Vibration Problems, Z. Dimitrova et al. (eds), Lisbon, Portugal, 9-12 September, 2013.

7.KNOX, K.J.; HAMMONS, M.I.; LEWIS, T.T.; PORTER, J.R., Polymer Materials for Structural Retrofit, Technical report, Tyndall AFB, Florida, 2000.

8.CRAWFORD, J.E.; SHENGRUI, L.; Design and implementation of protective technologies for improving blast resistance of buildings, Enhancing Building Security Seminar, Singapore, 2005. 
9.EL. SAYED, T.; MOCK, JR.W.; MOTA, A.; FRATERNALI, F.; ORTIZ, M., Comput. Mech., 43, no. 4, 2012, p. 525.

10.NURICK, G.N.; MARTIN, J.B.; IJIE, 8, no. 2, 1989, p.159.

11.XUE, Z;; HUTCHINSON, J.W., Mechanics of Materials, 39, 2007, p. 473.

12.AMINI, M.R.; NEMAT NASSER, S.; ISAACS, J .B., IJ IE, 37, 2010, p. 82. 13.MOHOTTI, D.; NGO, T.; MENDIS, P., RAMAN S.N., IJ MD, 52, 2013, p.1. 14.MOHOTTI, D.; ALI, M.; NGO, T.; LU, J .; MENDIS, P; RUAN, D., Materials and Design, 50, 2013, p. 413.
15.MOHOTTI, D.; NGO, T.; RAMAN S.N.; ALI, M.; MENDIS, P., Materials and Design, 56, 2014, p. 696.

16.BOKOBZA, L., Polymer, 48, 2007, p. 4907.

17.SENGUPTA, R.; CHAKRABORTY, S., et.al., Polym. Eng. Sci., 47, 2007, 1956.

18.MAITI, M.; BHATTCHARYA, M.; BHOWMICK, A.K., Rubber Chem. Technol., 81, 2008, p. 384.

19.MARK, J.E., Acc. Chem. Res., 39, 2006, p. 881.

20.LAU K-T.; GU, C.; HUI, D., Comp. B Eng., 7, 2006, p. 42

Manuscript received: 28.11 .2016 